\title{
Psychiatry in former East and West Germany since reunification
}

\author{
Manfred Baver
}

Discussion of the need to reform psychiatric services in former West Germany started relatively late. It was only in the late $1960 \mathrm{~s}$, when the government changed from the conservative Christian Democrats to a coalition of the Social Democratic and Liberal Parties, that psychiatry became a public issue for the first time since World War II. Parliament appointed an expert commission, which after four years gave a comprehensive report in which the inadequate care of mentally ill patients was criticised.

The main points of criticism were that the in-patient treatment of the mentally ill was mostly provided by badly staffed and remotely located large state mental hospitals, sometimes with 2000 or more beds; psychiatric facilities within the community were almost non-existent; out-patient services, especially for chronic mentally ill patients, were insufficient; and psychiatric treatment and care was mostly conducted outside the general medical system.

The expert commission proposed reforms that took into account internationally accepted standards and were modelled on the British system. The main focus of the proposals was on the creation of community based facilities and the link between in-patient and out-patient services, which until then had been strictly separated. The big state mental hospitals did not have outpatient departments and chronic mentally ill patients stayed an unnecessarily long time in hospital because there were no complementary and out-patient services within the community.

In West Germany this situation has improved significantly over the last 20 years. Between 1971 and 1994 almost 100 psychiatric departments have been organised in general hospitals. Most have about 80 beds and 20 places in daycare facilities. The number of psychiatric departments in general hospitals therefore exceeds the 78 large state mental hospitals still in existence. Including the 27 psychiatric university clinics, which are comparable to a psychiatric department, there are currently 125 departments in the western parts of Germany with about 12,000 beds. The average duration of a patient's stay is about 30 days and these facllities admit about 120,000 patients annually, which approximately equals the number admitted by state mental hospitals. Since all these departments are located close to mostly urban communities, it is a safe assumption that today far more than half of all psychiatric patients can be treated in their own community.

The majority of these departments serve a defined catchment area in which chronic patients are no longer sent to state mental hospitals but treated within the community. Almost all of these facilities have sheltered workshops, sheltered housing for psychiatric patients and often also day-centres and well equipped outpatient services. So far no state mental hospital has been closed down but their number of beds has been reduced dramatically. Hospitals which had 1500 beds 20 years ago have 400-500 today, sometimes less than 300 beds. The first of the state mental hospitals are expected to close before the year 2000 .

This development is not only supported by politicians and many young psychiatrists, but demanded by newly organised groups of relatives of the mentally ill. This caused a public recognition of psychiatry and a discussion about existing problems which speeded up the reforms and helped psychiatry move towards the community. However, there is still an ongoing discussion about the 'best way' among the profession. While the reform-orientated, mostly younger doctors, who work in the community think that progress is too slow, many hospital psychiatrists and administrators want to preserve the status quo. They argue that psychiatric departments in general hospitals and connected extramural and out-patient sevices will not be able to treat every patient and that state mental hospitals will still be necessary in the future. They also think that big hospitals are able to provide better care, since it requires a certain size of facility to provide specialised treatment for different groups of patients, e.g. depressive, schizophrenic, psychogeriatric and alcohol or drug addicts. Neither the patients, their relatives nor the politicians share this view, so that steady progress towards more community orientation and integration of psychiatric services can be expected, although slower than in the past since public funding has 
decreased from the level of the 1970s because of Germany's unification. There will also be regional differences because funding of health care system falls within the jurisdiction of the 16 Lönder which have different opinions about the structure of psychiatric care. The sparsely populated Saarland, for example, plans to close its only big state mental hospital by 1996 and to provide psychiatric beds only in general hospitals. Densely populated Bavaria, by contrast, adheres to the concept of large state mental hospitals, which have been modernised in recent years. Here only a few psychiatric departments in general hospitals have been created.

The mental health care system in former East Germany after World War II was almost the same as in West Germany. It was also based mainly on large psychiatric hospitals with 500 to 2000 beds. Out-patient care took place in out-patient departments that were typical in former socialist countries and there were no psychiatrists in private practice. These out-patient departments were intended to provide medical treatment as well as social care with a multiprofessional team of doctors, psychologists, social workers, nurses and other psycho-soctal professionals but rarely functioned satisfactorily because of insufficient staffing. Most of these out-patient departments have since been closed down and many of the doctors who used to work there are now in office practice, with most in the cities and only very few in the country. Compared to the former West German Länder, where there is one psychiatrist for every 20,000 people, the rates in the former East German Lainder is $1: 30,000$. But in the western parts of Germany there also exists a large number of psychologists and psychotherapists in office practice (about 1:10,000 population) while in former East Germany this number is very small.

In October 1993 a law came into effect that allows only the same number of doctors to start a private practice as retire, which means that the number of psychiatrists in office practice will remain at the level of 1993 . Therefore it will not be possible to improve the out-patient treatment of psychiatric patients through an increase in the number of psychiatrists in office practice. In this context it must be emphasised that many German studies came to the conclusion that the patients of psychiatrists in office practice differ from patients treated in hospitals and therefore many communities established complementary out-patient services especially for the treatment of chronic mentally 111 patients.

Until German reunification there were almost no sheltered workshops and other services offering rehabllitative care in East Germany. One reason was that many chronic mentally ill patients were integrated into the regular job market. During restructuring of the East
German economy after reunification, unemployment rose sharply and almost all mentally ill patients lost their jobs. Since the cost of housing also rose sharply and apartments are scarce, it is at present very difficult to develop a psychiatric infrastructure comparable to West German standards. However, there are promising initiatives in East Germany, especially where psychiatric departments in general hospitals have been created. These departments are best able to create initiatives for community based psychiatry because they are located in the community and part of a general hospital better accepted by the population than large state mental hospitals, which still carry unpleasant associations about the treatment of the mentally ill.

A special concern among many Germans, and not only psychiatrists, after reunification was whether in former East Germany there had been an abuse of psychiatry comparable with the one in the former Soviet Union. Four years after reunification this can be answered with 'no'. Although there were frequent attempts in former East Germany to employ psychiatrists politically, no case was found where a political dissident was given a psychiatric diagnosis and treated accordingly in a special psychiatric hospital. However, many psychiatrists who held senior posts as hospital directors and university professors had either worked for the secret service (Stasi) or provided them with medical information about certain patients. When this was uncovered the psychiatrists lost their posts and now work in office practice or private hospitals. The controversy about the political involvement of psychiatrists which was very heated only two years ago has now almost disappeared since the problem has been solved in this way.

\section{Conclusions}

In terms of international comparisons, the West German psychiatric reform took an intermediate path. With significant regional differences the size of large state mental hospitals has signifcantly decreased, but none has been yet closed. Almost 100 psychiatric departments in general hospitals have been created during the last 20 years, most consisting of about 80 beds and a day hospital, and are responsible for a catchment area of about 150,000 inhabitants. This system works best in towns with 100,000 150,000 inhabitants. Many places have succeeded in adding a variety of extramural and out-patient services (e.g. sheltered workshops, sheltered housing, day-centres, out-patient facilities, etc.) to their psychiatric infrastructure. The relatively high number of psychiatrists (1:20,000 population) and psychologists/ 
psychotherapists (1:10,000 population) in office practice has also contributed to the situation that out-patient care of mentally ill patients within the community is satisfactory. Nevertheless, a number of old chronic mentally ill patients are still in psychiatric hospitals because up to now there were no adequate services within the community for them.

In East Germany the reform of psychiatry essentially started only after reunification. Therefore the large state mental hospitals are still very prevalent there. An out-patient psychiatric infrastructure comparable to that in West Germany will slowly develop over the next few years. The psychiatric departments in general hospitals will be the engine of this development. There already are promising attempts, mostly in medium-sized cities. Because financial resources are more scarce and the political priorities of 1994 are different from 1974, this process in the East will probably take longer than in West Germany. This means that in almost every area of society, the gap between West and East Germany will continue for many more years.

M. Bauer, Professor, Städtlsche Kltniken Offenbach, Psychiatrische Klinik, Starkenburgring 66, 63069 Offenbach, Germany

\title{
East and west, old and new: the College tour of Germany
}

\author{
S.D. Martin, B. Bende, B. Breitner, M. Laker and F. Leslie
}

German psychiatry is emerging from a black past to a challenging future. Under the Nazis it is thought that about 100,000 psychiatric patients were killed and 300,000 were compulsorily sterilised. Services for the mentally ill had also been adversely affected by two world wars and recession. For 50 years there was little progress. By the 1970 s, the government and other institutions took more interest in mental health. Community facilities began to appear such as day centres. Long-stay patients are now being discharged from hospitals and asylums have closed in some states.

On 26 September 1993, a party of 26 psychlatrists went on a week-long Study Tour to Northern Germany visiting Lübeck, Kiel, Rostock and Hamburg. It was admirably organised by Dr Cyril Davies from the British side and Dr Alexander Boroffka from the German Association for Psychiatry and Neurology.

\section{Health insurance}

It is mandatory for anybody in training or employment in Germany to have health insurance. Unemployed people or those receiving social benefits are also included.
Health insurance organisations pay doctors in their own practice every three months for their patient contacts and interventions with itemised fees. Insurance organisations, together with local government, negotiate contracts with individual hospitals for in-patient treatment. Recent research has shown $20 \%$ of the population have had insurance payments for some kind of mental health treatment.

Rehabilitation services, including addictions, are often funded by health insurance organisations and pension funds who, as purchasers, can restrict funding and prevent treatment.

\section{Private practice}

Hospital psychiatrists see almost exclusively inpatients. Most out-patient treatment is provided by specialists in their own practices in the community. Usually called 'private practice' the term is misleading as health insurance organisations pay for treatment. The system allows patients to choose psychiatrists but they must usually arrange their own follow-up after discharge from hospital.

There is very little multidisciplinary team work. Psychiatrists in their own practice are 